\title{
Recovery of lipase derived from Burkholderia cenocepacia ST8 using sustainable aqueous two-phase flotation composed of recycling hydrophilic organic solvent and inorganic salt.
}

\begin{abstract}
Recycling hydrophilic organic solvent/inorganic salt aqueous two-phase flotation (ATPF) is a novel, low cost, green and high efficient technique for recovery of biomolecules. Recycling ATPF composed of 2-propanol and potassium phosphate was developed for sustainable separation, concentration and purification of Burkholderia cenocepacia ST8 lipase from liquid fermentation broth. Thirteen parameters upon recycling hydrophilic organic solvent/inorganic salt ATPF performance were investigated. The optimum conditions for this recycling ATPF were determined to be $40 \mathrm{~mL}$ volume of $50 \%(\mathrm{w} / \mathrm{w}) 2$-propanol, $1.0 \mathrm{~L}$ of 250 $\mathrm{g} / \mathrm{L}$ of potassium phosphate, $\mathrm{pH} 8.5,100 \%$ (v/v) of crude feedstock, $30 \mathrm{~mL} / \mathrm{min}$ of $\mathrm{N} 2$ flow rate for $30 \mathrm{~min}$ in a $8 \mathrm{~cm}$ radius of colorimeter tube with G4 porosity $(5-15 \mu \mathrm{m})$ sintered glass disk. A purification factor of $14.4 \pm 0.04$ and a lipase yield of $99.2 \pm 0.03 \%$ were achieved in this optimized ATPF. The recycling of phase-forming components employed at the end of recovery process was based on the principals of green chemistry, with high efficiency and economical viability. There was no gross variation of results during the process of scaling-up. Therefore, this novel recycling ATPF is feasible to be applied at industrial-scale.
\end{abstract}

Keyword: Enzymes; Biocatalysis; Alcohols; Aalt effect 